\title{
85698 - SUICÍDIO EM LONGEVOS NO RS: DADOS DO DATASUS 2017
}

\author{
Pôster - Gerontologia
}

Ilva Inês Rigo / Rigo, II / PUCRS; Ana Paula Tiecker / Tiecker / PUCRS; Marlon Cássio Pereira Grigol / Grigol, MCP / PUCRS; Ângelo José Gonçalves Bós / Bós, AJG / PUCRS

A taxa de suicídio em idosos é o dobro do que acontece nas outras faixas etárias. ${ }^{1 ; 2}$ Entre as causas de suicídio, em idosos jovens estão doenças psiquiátricas ${ }^{3}$ e questões sociais ${ }^{4}$. Entretanto, pouco se sabe sobre as características do suicídio em idades avançadas em que o processo de envelhecimento se torna mais exacerbado tornando esses idosos mais vulneráveis. Compreender esse processo pode embasar o desenvolvimento de políticas públicas para sua prevenção. Objetivo: Estudar o perfil das mortes por suicídio entre longevos no Rio Grande do Sul (RS) em 2017. Método: Foram analisados os dados do Sistema de Informação de Mortalidade (SIM) do DATASUS referentes aos óbitos por suicídio em longevos, no RS em 2017. Resultados: No ano de 2017, no foram relatados no SIM no RS 65 óbitos por suicídio entre longevos, dos quais 83,1\% eram homens, $86,1 \%$ brancos, $40 \%$ casados e 24,6\% viúvos, até 7 anos de estudo (49,2\%). Quanto ao local de ocorrência, $80 \%$ foi no domicílio. Quanto à causa básica, 56,9\% foi enforcamento, 15,4\% arma de fogo e ferimentos cortantes ou penetrantes $(7,7 \%)$. Somente $1,5 \%$ tinha registro de transtorno mental. Conclusões: O perfil dos longevos que faleceram por suicídio em 2017 no RS foi de homens, casados, com baixa escolaridade e sem transtorno mental associado, o local de ocorrência mais frequente foi o domicílio e por enforcamento, corroborando com a literatura. A inexistência de transtorno mental surpreende não indo ao encontro com dados encontrados na literatura.

Referências: 1. KEGLER, Scott R.; STONE, Deborah M.; HOLLAND, Kristin M. Trends in suicide by level of urbanization-United States, 1999-2015. MMWR. Morbidity and mortality weekly report, v. 66, n. 10, p. 270, 2017; 2. DO NASCIMENTO CARVALHO, Igho Leonardo et al. A intoxicação por psicofármacos com motivação suicida: uma caracterização em idosos. Revista Brasileira de Geriatria e Gerontologia, v. 20, n. 1, 2017; 3. BARROSO, Marianna Leite et al. A depressão como causa do desenvolvimento da ideação suicida na pessoa idosa e as consequências no âmbito familiar. Id on Line REVISTA DE PSICOLOGIA, v. 12, n. 41, p. 66-76, 2018; 4. MINAYO, M.C.S.; FIGUEIREDO, A.E.; MANGAS, R.M.N. Estudo das publicações científicas (2002-2017) sobre ideação suicida, tentativas de suicídio e autonegligência de idosos internados em Instituições de Longa Permanência. Ciência \& Saúde Coletiva, v. 24, p. 1393-1404, 2019. 